Supporting Information

\title{
Self-Assembling Peptide Artificial Enzyme as Efficient Detection Probers and Inhibitor for Cancer Cells
}

Meiling Lian, Shuo Zhang, Jun Chen, Xuejiao Liu, Xu Chen*, and Wensheng Yang*

State Key Laboratory of Chemical Resource Engineering, Beijing University of

Chemical Technology, Beijing 100029, P. R. China

*Corresponding author. Tel.: +86 10 64435271; fax: +86 1064425385 .

E-mail address: chenxu@mail.buct.edu.cn; yangws@mail.buct.edu.cn 
Table S1. Comparison of the Michaelis-Menten kinetics parameters obtained in this work with other reports.

\begin{tabular}{|c|c|c|c|c|}
\hline Electrodes & Substance & $\mathrm{Km} / \mathrm{mM}$ & $\mathrm{Vmax} / 10^{-8} \mathrm{M} \mathrm{s}^{-1}$ & Reference \\
\hline \multirow{3}{*}{ HRP } & TMB & 0.434 & 10.00 & \multirow{3}{*}{1} \\
\hline & & & & \\
\hline & $\mathrm{H}_{2} \mathrm{O}_{2}$ & 3.702 & 8.71 & \\
\hline \multirow{3}{*}{ Pt NCs } & TMB & 0.096 & 14.14 & \multirow{3}{*}{2} \\
\hline & & & & \\
\hline & $\mathrm{H}_{2} \mathrm{O}_{2}$ & 3.07 & 18.17 & \\
\hline \multirow{3}{*}{$\mathrm{Fe}_{3} \mathrm{O}_{4} @ \mathrm{C} \mathrm{YSNs}$} & TMB & 0.27 & 12.0 & \multirow{3}{*}{3} \\
\hline & & & & \\
\hline & $\mathrm{H}_{2} \mathrm{O}_{2}$ & 0.035 & 3.34 & \\
\hline \multirow{3}{*}{ PBNPs } & TMB & 0.337 & 21.6 & \multirow{3}{*}{4} \\
\hline & & & & \\
\hline & $\mathrm{H}_{2} \mathrm{O}_{2}$ & 14.7 & 11.5 & \\
\hline Fmoc-RGD/hemin & TMB & 0.132 & 14.7 & \multirow[b]{2}{*}{ This work } \\
\hline NPs & $\mathrm{H}_{2} \mathrm{O}_{2}$ & 2.09 & 22.2 & \\
\hline
\end{tabular}


Table S2. Linear range and LOD of different nanoenzyme-based colorimetric sensor for detection of $\mathrm{H}_{2} \mathrm{O}_{2}$.

\begin{tabular}{|c|c|c|c|}
\hline Electrodes & Linear range $(\mu \mathrm{M})$ & $\begin{array}{c}\text { Limit of } \\
\text { detection }(\mu \mathrm{M})\end{array}$ & Reference \\
\hline $\mathrm{Pt}$ NCs & $0-200$ & 0.46 & 2 \\
\hline $\mathrm{Fe}_{3} \mathrm{O}_{4} @ \mathrm{C}$ & $1-20$ & 0.39 & 3 \\
\hline GQDs/AgNPs & $0.1-100$ & 0.033 & 5 \\
\hline AuNPs-Fe ${ }^{2+}$ & $0-20000$ & 0.1 & 6 \\
\hline Porous PtPd nanorods & $0.02-50000$ & 0086 & 7 \\
\hline $\mathrm{s} \gamma-\mathrm{Fe}_{2} \mathrm{O}_{3} / \mathrm{SiO}_{2}$ & $1-100$ & 0.0106 & 8 \\
\hline $\mathrm{NiCo}_{2} \mathrm{O}_{4}$ hollow sphere & $10-400$ & 0.21 & 9 \\
\hline $\mathrm{V}_{2} \mathrm{O}_{5}$ & $1-500$ & 1 & 10 \\
\hline Fmoc-RGD/hemin NPs & $1-1000$ & 0.3 & This work \\
\hline
\end{tabular}


Table S3. Comparison of Different Methods for the Analysis of Tumor Cells.

\begin{tabular}{cccc} 
Detection method & Linear range $(\mu \mathrm{M})$ & $\begin{array}{c}\text { Limit of } \\
\text { detection }(\mu \mathrm{M})\end{array}$ & Reference \\
\hline colorimetric & $100-10000$ & 40 & 11 \\
colorimetric & $30-8000$ & 30 & 12 \\
colorimetric & $100-1000$ & 100 & 13 \\
colorimetric & $50-500$ & 50 & 14 \\
electrochemical & $100000-$ & 100000 & 16 \\
detection & 100000000 & & This work \\
ICP-MS & $200-12000$ & 51 & 50 \\
\hline colorimetric & $50-10000$ & & \\
\hline
\end{tabular}



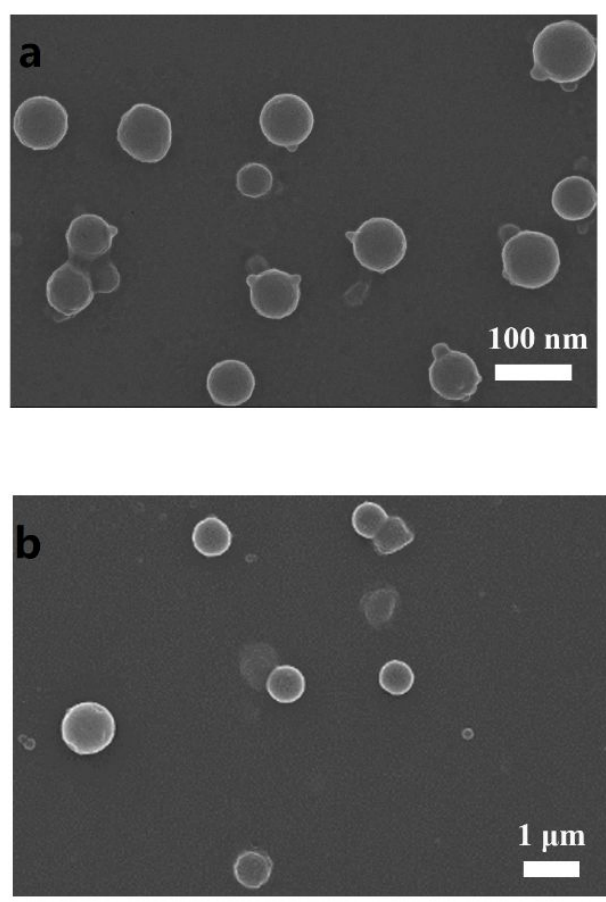

Figure S1. Typical SEM images of (a) Fmoc-FF/hemin NPs and (b) FF/hemin NPs.

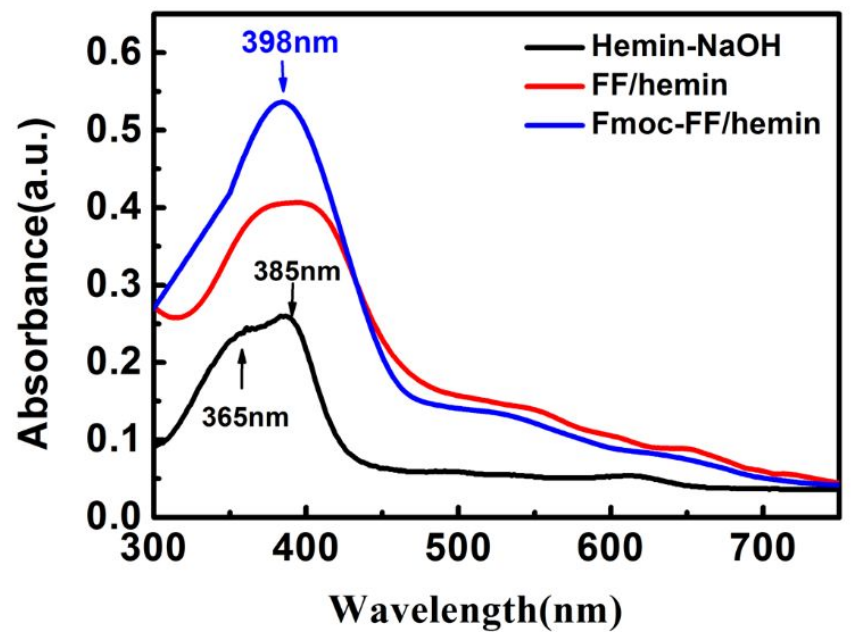

Figure S2. UV-vis spectra of free hemin in $0.2 \mathrm{M} \mathrm{NaOH}$ aqueous solution and hemin in the peptide. 

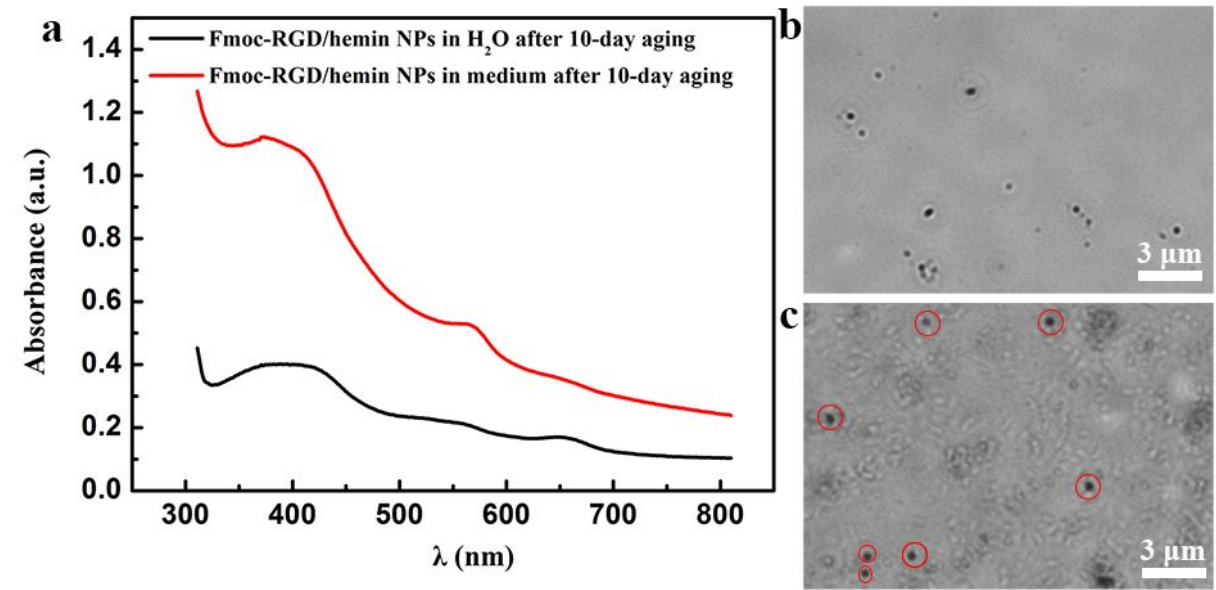

Figure S3. (a) UV-vis spectra of $\mathrm{f}$ Fmoc-RGD/hemin NPs in $\mathrm{H}_{2} \mathrm{O}$ and medium after 10-day aging. Microscope image of Fmoc-RGD/hemin NPs after 10-day aging in (b) $\mathrm{H}_{2} \mathrm{O}$ and (c) cell culture medium.

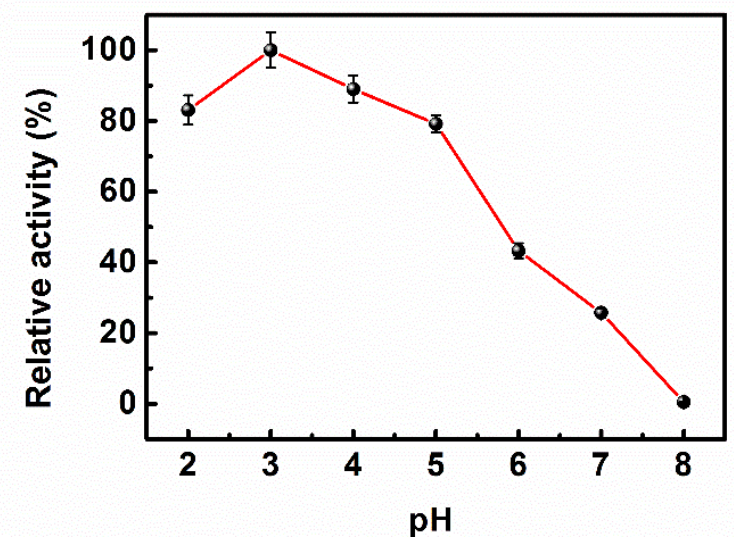

Figure S4. The absorbance changes with the $\mathrm{pH}$ from 2 to 8 . 

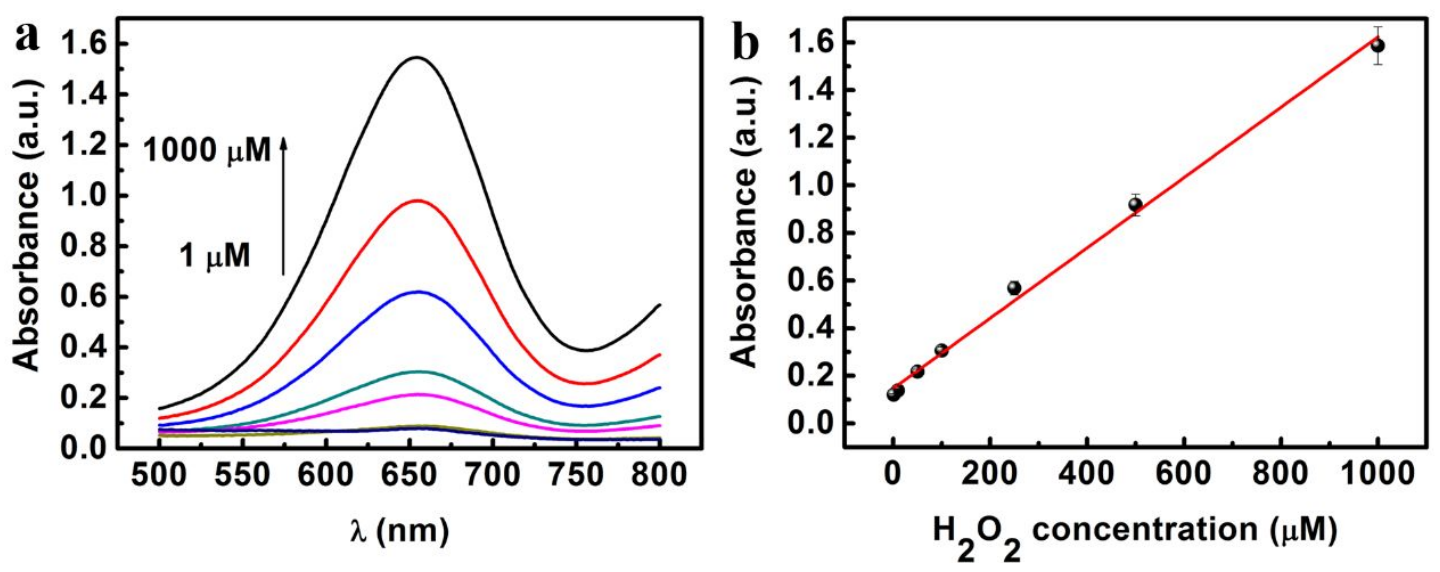

Figure S5. (a) The absorption spectra of Fmoc-RGD/hemin NPs and TMB system upon adding various concentrations of $\mathrm{H}_{2} \mathrm{O}_{2}(1-1000 \mu \mathrm{M}$, from bottom to top). (b) The linear regression to plots of the absorbance with the $\mathrm{H}_{2} \mathrm{O}_{2}$ concentration.

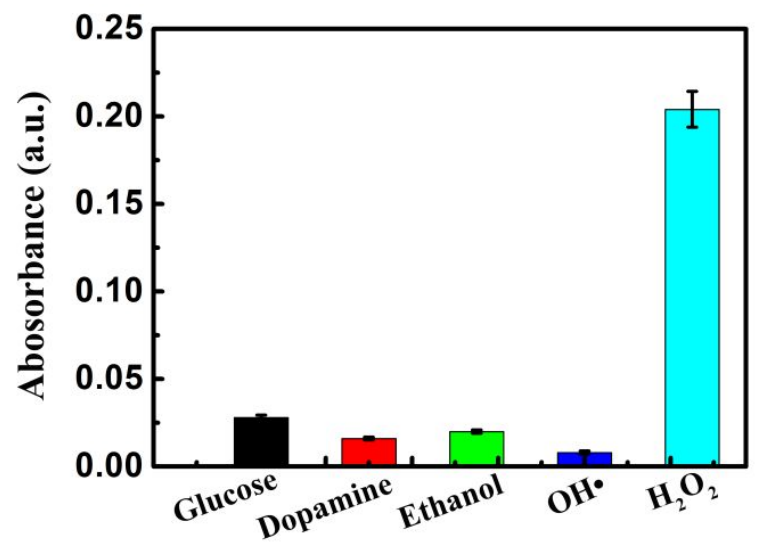

Figure S6. Selectivity of Fmoc-RGD/hemin NPs based $\mathrm{H}_{2} \mathrm{O}_{2}$ assay.
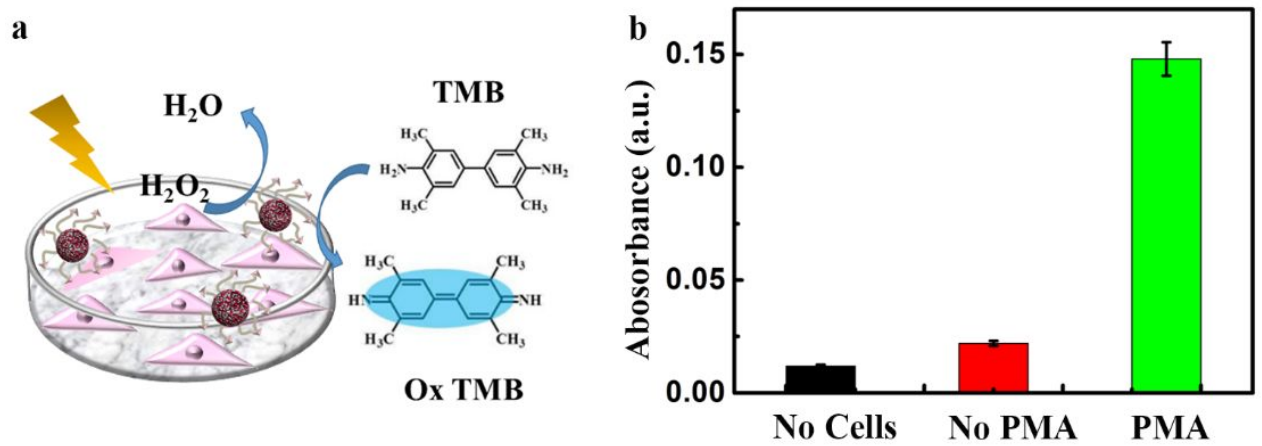

Figure S7. (a) Schemes of colorimetric detection of cellular $\mathrm{H}_{2} \mathrm{O}_{2}$. (b) The absorbance of the sensing system to detection of $\mathrm{H}_{2} \mathrm{O}_{2}$ release from MCF-7 induced by PMA. 


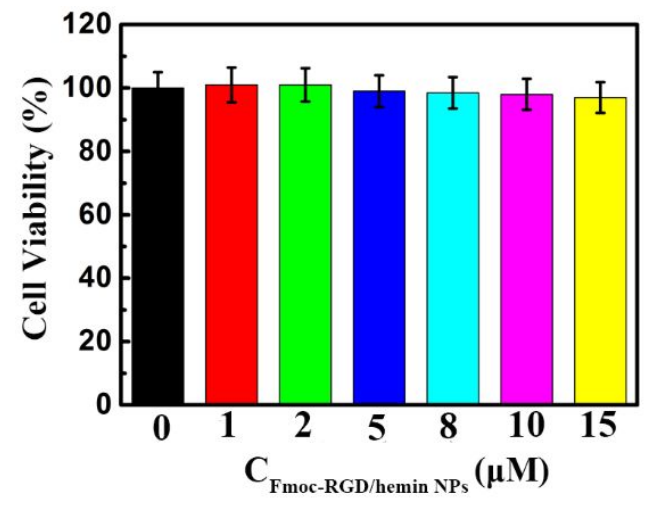

Figure S8. Relative viability of MFC-7 cells incubated with a series of gradient concentrations of Fmoc-RGD/hemin NPs.

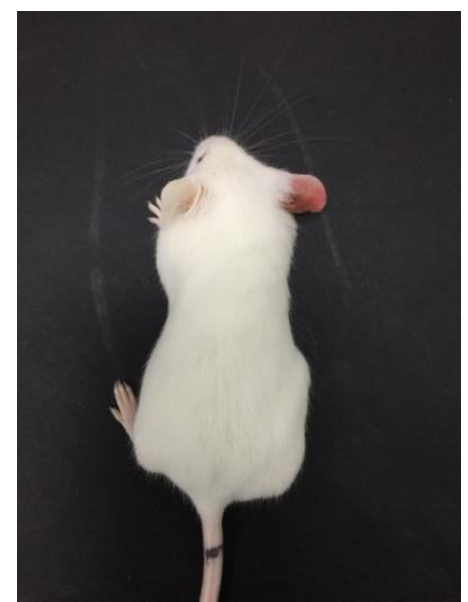

Figure S9. Photograph of a live mouse, showing an inflammatory ear (right) induced by PMA.

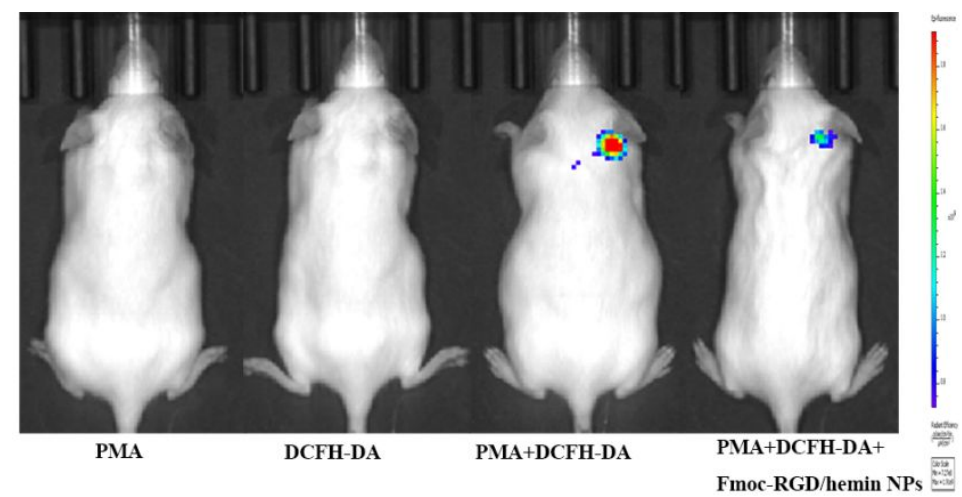

Figure S10. In vivo fluorescence images show mice with PMA-induced ear inflammation after treatments with different materials. 

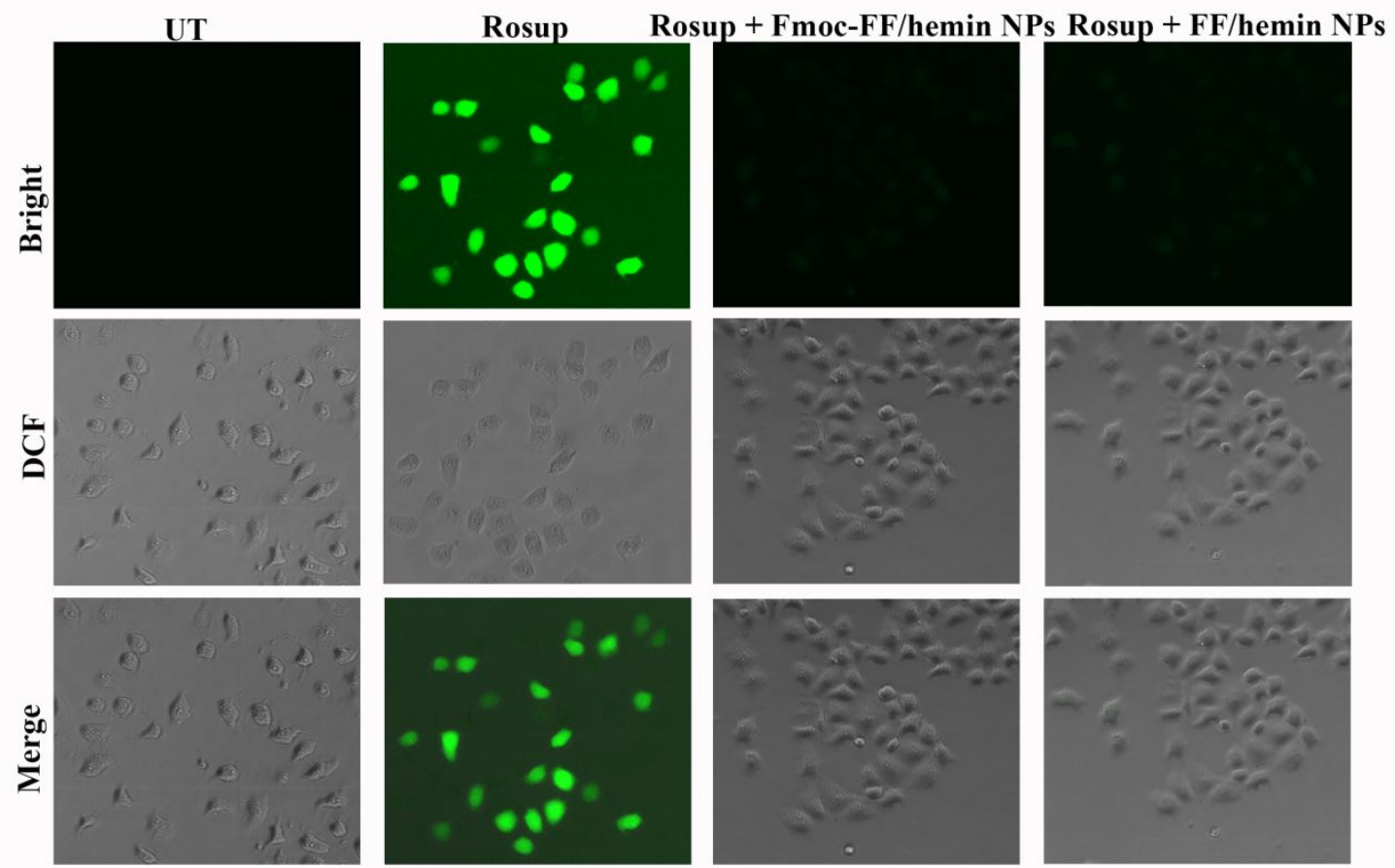

Figure S11. Fluorescence images of cells with different treatments.

\section{References:}

(1) Gao, L., Zhuang, J., Nie, L., Zhang, J., Zhang, Y., Gu, N., Wang, T., Feng, J., Yang, D., Perrett, S., Yan, X. Intrinsic Peroxidase-like Activity of Ferromagnetic Nanoparticles. Nat. Nanotechnol. 2007, 2, 577.

(2) Jin, L., Meng, Z., Zhang, Y., Cai, S., Zhang, Z., Li, C., Shang, L., Shen, Y. Ultrasmall Pt Nanoclusters as Robust Peroxidase Mimics for Colorimetric Detection of Glucose in Human Serum. ACS Appl. Mater. Interfaces 2017, 9, $10027-10033$.

(3) Lu, N., Zhang, M., Ding, L., Zheng, J., Zeng, C., Wen, Y., Liu, G., Aldalbahi, A., Shi, J., Song, S., Zuo, X., Wang, L. Yolk-shell Nanostructured Fe $\mathrm{O}_{4} @$ $\mathrm{C}$ Magnetic Nanoparticles with Enhanced Peroxidase-Like Activity for Label-Free Colorimetric Detection of $\mathrm{H}_{2} \mathrm{O}_{2}$ and Glucose. Nanoscale 2017, 9, 4508-4515.

(4) Zhang, W., Hu, S., Yin, J. J., He, W., Lu, W., Ma, M., Gu, N., Zhang, Y. Prussian Blue Nanoparticles as Multienzyme Mimetics and Reactive Oxygen Species Scavengers. J. Am. Chem. Soc. 2016, 138, 5860-5865.

(5) Chen, S., Hai, X., Chen, X. W., Wang, J. H. In Situ Growth of Silver Nanoparticles 
on Graphene Quantum Dots for Ultrasensitive Colorimetric Detection of $\mathrm{H}_{2} \mathrm{O}_{2}$ and Glucose. Anal. Chem. 2014, 86, 6689-6694.

(6) Xu, C., Ren, J., Feng, L., Qu, X. $\mathrm{H}_{2} \mathrm{O}_{2}$ Triggered Sol-Gel Transition Used for Visual Detection of Glucose. Chem. Commun. 2012, 48, 3739-3741.

(7) Ge, S., Liu, W., Liu, H., Liu, F., Yu, J., Yan, M., Huang, J. Colorimetric Detection of the Flux of Hydrogen Peroxide Released from Living Cells Based on the High Peroxidase-Like Catalytic Performance of Porous PtPd Nanorods. Biosens. Bioelectron. 2015, 71, 456-462.

(8) Lu, C., Liu, X., Li, Y., Yu, F., Tang, L., Hu, Y., Ying, Y. Multifunctional Janus Hematite-Silica Nanoparticles: Mimicking Peroxidase-Like Activity and Sensitive Colorimetric Detection of Glucose. ACS Appl. Mater. Interfaces 2015, 7, 15395-15402.

(9) Huang, W., Lin, T., Cao, Y., Lai, X., Peng, J., Tu, J. Hierarchical $\mathrm{NiCo}_{2} \mathrm{O}_{4}$ Hollow Sphere as A Peroxidase Mimetic for Colorimetric Detection of $\mathrm{H}_{2} \mathrm{O}_{2}$ and Glucose. Sensors 2017, 17, 217

(10) Sun, J., Li, C., Qi, Y., Guo, S., Liang, X. Optimizing Colorimetric Assay Based on $\mathrm{V}_{2} \mathrm{O}_{5}$ Nanozymes for Sensitive Detection of $\mathrm{H}_{2} \mathrm{O}_{2}$ and Glucose. Sensors 2016, 16,584 .

(11) Zhang, X., Xiao, K., Cheng, L., Chen, H., Liu, B., Zhang, S., Kong, J. Visual and Highly Sensitive Detection of Cancer Cells by A Colorimetric Aptasensor Based on Cell-Triggered Cyclic Enzymatic Signal Amplification. Anal. Chem. 2014, 86, $5567-5572$

(12) Zhang, L. N., Deng, H. H., Lin, F. L., Xu, X. W., Weng, S. H., Liu, A. L., Lin, X. H., Xia, X. H., Chen, W. In Situ Growth of Porous Platinum Nanoparticles on Graphene Oxide for Colorimetric Detection of Cancer Cells. Anal. Chem. 2014, 86, $2711-2718$

(13) Kim, M. I., Kim, M. S., Woo, M. A., Ye, Y., Kang, K. S., Lee, J., Park, H. G. Highly Efficient Colorimetric Detection of Target Cancer Cells Utilizing Superior Catalytic Activity of Graphene Oxide-Magnetic-Platinum Nanohybrids. Nanoscale 2014, 6, 1529-1536. 
(14) Ye, X., Shi, H., He, X., Wang, K., He, D., Yan, L. A., Xu, F., Lei, Y., Tang, J., $\mathrm{Yu}, \mathrm{Y}$. Iodide-Responsive $\mathrm{Cu}-\mathrm{Au}$ Nanoparticle-based Colorimetric Platform for Ultrasensitive Detection of Target Cancer Cells. Anal. Chem. 2015, 87, 7141-7147.

(15) Arya, S. K., Wang, K. Y., Wong, C. C., Rahman, A. R. A. Anti-EpCAM Modified LC-SPDP Monolayer on Gold Microelectrode Based Electrochemical Biosensor for MCF-7 Cells Detection. Biosens. Bioelectron. 2013, 41, 446-451.

(16) Yang, B., Chen, B., He, M., Yin, X., Xu, C., Hu, B. Aptamer-Based DualFunctional Probe for Rapid and Specific Counting and Imaging of MCF-7 Cells. Anal. Chem. 2018, 90, 2355-2361. 